\title{
A Systematic Mapping of Current Literature on Sustainability at Farm-Level in Beef and Lamb Meat Production
}

\author{
Katarina Arvidsson Segerkvist ${ }^{1, *(D)}$, Helena Hansson ${ }^{2} \mathbb{D}$, Ulf Sonesson ${ }^{3}$ and Stefan Gunnarsson ${ }^{1}$ (D) \\ 1 Department of Animal Environment and Health, Swedish University of Agricultural Sciences (SLU), \\ P.O. Box 234, S-53223 Skara, Sweden; stefan.gunnarsson@slu.se \\ 2 Department of Economics, Swedish University of Agricultural Sciences (SLU), P.O. Box 7013, \\ S-75007 Uppsala, Sweden; helena.hansson@slu.se \\ 3 RISE Research Institutes of Sweden, P.O. Box 5401, S-40229 Göteborg, Sweden; ulf.sonesson@ri.se \\ * Correspondence: katarina.segerkvist@slu.se; Tel.: +46-51-16-7144
}

Citation: Arvidsson Segerkvist, K.;

Hansson, H.; Sonesson, U.;

Gunnarsson, S. A Systematic

Mapping of Current Literature on

Sustainability at Farm-Level in Beef and Lamb Meat Production.

Sustainability 2021, 13, 2488.

https://doi.org/10.3390/su13052488

Academic Editor: Ada Braghieri

Received: 28 January 2021

Accepted: 20 February 2021

Published: 25 February 2021

Publisher's Note: MDPI stays neutral with regard to jurisdictional claims in published maps and institutional affiliations.

Copyright: (c) 2021 by the authors. Licensee MDPI, Basel, Switzerland. This article is an open access article distributed under the terms and conditions of the Creative Commons Attribution (CC BY) license (https:// creativecommons.org/licenses/by/ $4.0 /)$.

\begin{abstract}
Beef and lamb meat production is associated with important cultural, economic and environmental impacts in most countries worldwide. However, it is also related with sustainability challenges. To enable cattle and sheep farming to develop in line with sustainability, existing knowledge need to be implemented and identified knowledge gaps filled. The purpose of this article was to systematically map the scientific literature on environmental, economic and social sustainability at farm-level beef and lamb meat production to identify knowledge gaps and to point to important future actions and areas of research. Papers published January 2000-August 2020 with a geographical origin in Europe, Northern America, and Australia-New Zealand were included. The systematic literature search resulted in a total of 1355 hits; however, after removing papers which were considered out of the scope of the study, and duplicate papers, only 22 and 11 papers related to beef and sheep farming, respectively were retained for further analysis. Of these, only 11 in total included all three sustainability dimensions. Several papers only mentioned one or two of the sustainability dimensions or put them in relation to that/those main dimension covered, thus limiting the extent to which possible synergies or tradeoffs between different sustainability aspects actually can be studied. This indicates a need for a more comprehensive approach when studying farm-level sustainability. Future research would benefit from a more holistic approach and include all dimensions of sustainability within the same study. Further, focus should also be on how to measure and assess sustainability aspects in a standardized way.
\end{abstract}

Keywords: sheep; cattle; animal welfare; life cycle assessment; sustainable production

\section{Introduction}

Cattle (Bos taurus) and sheep (Ovis aries) farming for meat production is associated with important cultural, economic, and environmental impacts in most countries worldwide. In particular, livestock production contributes in important ways to improving the quality of everyday life of many societies, since it provides an income for many families and helps to meet the demand for food and ensure regional and global food security. As such, beef and lamb meat farming contributes to several of the 17 global Sustainable Development Goals (SDG) set by the United Nations. In this respect, it contributes in particular to SDG1: zero hunger, SDG3: good health and wellbeing, and SDG8: decent work and economic growth [1,2]. At the same time, beef and lamb meat farming may compromise other SDGs, for instance SDG13: climate action and SDG15: life on land. In 2018, global beef and sheep meat production was around 67 and 10 million tons per year, respectively, which corresponded to an increase of 76\% and 77\%, respectively, between 1970 and 2018 . Over the same period, the number of cattle reared for meat production increased by $44 \%$ and the number of sheep by $56 \%$, resulting in 302 million cattle and 574 million sheep worldwide in 2018 [3]. 
There is an increasing demand among consumers for food products to be produced in a sustainable way, and consumers are more and more considering the ethics of production methods when evaluating product quality [4]. Further, there is increasing awareness of the environmental challenges agricultural production is facing, constant pressure on farm incomes, and animal welfare concerns, which have paved the way for a growing interest in sustainable animal food production [5].

Sustainable development has since been defined as 'development that meets the needs of the present without compromising the ability of future generations to meet their own needs' [6]. There exists no universal definition of sustainable livestock production, however work by Torp-Donner and Juga [7] described it as the type of production that take both biodiversity and the environmental impacts beyond biodiversity into consideration, and is ethically and economically sound and ecologically sound. Tilman et al. [8] described sustainable agricultural production as the utilization and management of agricultural lands in such a way that it can keep its productivity, vitality, regenerative capacity and biological diversity, both today and in the future. Furthermore, it should contribute to significant social, economic and ecological functions locally, nationally as well as globally. [8]. This means that a sustainable production system must integrate and meet targets at all three dimensions of sustainability, i.e., environmental, economic, and social.

Today, more than $70 \%$ of the world's agricultural land is used for livestock production, either as land for grazing or as land to grow animal feed [9]. In order not to compete with cultivation of foods directly edible for humans, it becomes more and more important to use products which cannot be directly consumed by humans as animal feed and to a greater extent use lands for animal feed production that are not suitable for production of food products for direct human consumption. Ruminants can eat grass, leaves, and other fibrous materials that humans cannot eat, and convert them into milk and meat. Hence, if they are not fed grain to a large extent, ruminant production systems can be both sustainable and valuable and can contribute to better use of world's resources [10].

Ruminant livestock systems are related to considerable sustainability challenges. Emissions of greenhouse gases (GHG) to the atmosphere is one of the most pressing. Gerber et al. [11] estimated that about $40 \%$ of all livestock GHG emissions originate from beef production and its supply chains. Methane $\left(\mathrm{CH}_{4}\right)$ is the dominant source of GHG emissions from ruminant farming systems, where enteric fermentation in the rumen comprises the majority [12]. Production of GHG is strongly correlated with the dry matter intake of the animal, since the more feed it consumes, the more methane is produced [13]. Hence, increased production efficiency would not only increase the profitability, but also improve the environmental performance of beef cattle and sheep/lamb meat farming systems [14]. Further, there are reports suggesting that beef production uses too much of the world's resources [15]. However, many of these reports refer mainly to feedlot systems, and beef production systems differ significantly in aspects such as the amount of land and water used. Broom [10] showed that data referring only to feedlot systems are misleading and are invalid for understanding the most sustainable beef production systems, e.g., conserved water use (rainfall not included) is eight times higher in feedlots compared with silvo-pastoral systems. To evaluate the sustainability of a food production system, it is important to take aspects related to all sustainability dimensions into consideration. These aspects include the use of land and water, but also social sustainability, animal welfare, economic sustainability, and environmental impacts including pollution, biodiversity and global climate [16]. Furthermore, all sustainability aspects needs to be evaluated simultaneously [17,18], and all individual aspects can make the production system unsustainable [10]. Furthermore, for a production system to function, its economic viability is also essential. Beef and lamb meat production is most often performed by private firms and, in order for these firms to survive, their economic results are instrumental. Ignoring the economic sustainability of agriculture may lead to reduced interest among farmers in necessary investments and measures to improve environmental impacts and social conditions, or even in remaining in production [18]. Farmers' sense of wellbeing and quality of life, which 
is an essential part of social sustainability, is influenced for instance by social relations and technical solutions within production $[19,20]$. The societal acceptance of agricultural practices is also related to social sustainability. One aspect of this is the public's concerns about farm animal welfare [21,22], as it is directly linked to human acceptance of about livestock production methods. Agriculture can be also expected to contribute to rural economic growth and attractiveness which also likes with the social sustainability of rural communities [18]. Animal production is an important value-adding activity in rural areas compared with arable farming, where a larger share of the total supply chain value-adding occurs away from the farm. Therefore, sustainable development of agriculture is really a result of all three dimensions of sustainable development.

Different dimensions of sustainability in beef cattle and sheep farming have been examined in many studies. However, to date, there is no comprehensive overview of the research field that summarizes the state of the art in this area. The development of more sustainable cattle and sheep production systems would benefit from such an overview. This could be used as a basis to identify knowledge gaps. It could also be used to point to important future actions and areas of research. Accordingly, in this study we conducted a systematic map of the scientific literature related to sustainability at the farm-level in cattle and sheep production system. The study was limited to original work conducted in Europe, Northern America, Australia and New Zealand. This enabled a focus on production systems that are established in similar economic and institutional contexts.

\section{Materials and Methods}

The research presented in this paper is part of a larger project about sustainability in livestock production. Findings related to dairy [23], pig [24], finfish [25] and egg and chicken meat [26] production at farm-level have been published previously.

\subsection{Definition of Fundamental Concepts within Sustainability}

Sustainability is a holistic concept, but dividing it into different dimensions facilitates the implementation of an empirical analysis. The outcome can then provide a foundation for further scientific analyses on a higher level, e.g., to evaluate possible synergies or tradeoffs between, and within, the different dimensions of sustainability. When investigating the overall sustainability of a specific production system, it is crucial to include both the environmental, economic and social dimensions. In the present study, the three sustainability dimensions were defined as described below.

\subsubsection{Environmental Sustainability}

The environmental dimension of sustainability includes all human impacts on ecosystems and the natural resource base. There are many methods for analyzing environmental sustainability, among which quantified methods dominate. These methods differ in terms of aggregation, geographical coverage, focus, and environmental dimension, and in the scope of quantification with a product or production focus. For agriculture as a food producer, life cycle assessment (LCA) is the most established method, in research and business and by authorities. LCA is product-focused, i.e., it quantifies impacts for a specific product regardless of economic ownership, e.g., typical results are "impacts per $\mathrm{kg}$ bone-free meat at retail" [22]. The LCA framework includes all aspects of human impacts on ecosystems and use of natural resources, but the aspects included are determined by the aim of the study. This is a way to reduce the costs of performing an LCA but it means that LCA studies covering all aspects are extremely rare. More often, limited numbers of environmental aspects are included, in agricultural analyses typically climate impact, plant nutrient-related impacts, and use of land and energy. Other methods for quantifying environmental impacts share the systems approach with LCA, and to some extent also the assessment of impacts. The ecological footprint approach, which is also well established, aggregates all impacts on ecosystems and use of resources into a single unit, a hypothetical 
area needed to absorb impacts and regenerate resources. This simplifies comparisons, but complicates understanding of the causes of impacts [23].

\subsubsection{Economic Sustainability}

Research to date has not clearly established how economic sustainability is best measured [27], but standards for sustainability accounting such as the Global Reporting Initiatives [28] represent a useful attempt to provide guidelines from an accounting perspective. The Global Reporting Initiatives [28] highlight economic indicators such as revenues, profits, investments, and costs. From a theoretical point of view, there are two possible perspectives on economic sustainability. The first focuses on the use of natural resources within an economic system and view sustainable economic activity as being undertaken in such a way that natural resources are not harmed. In this perspective, the concept of externalities is useful in conceptualizing and fully capturing all costs associated with production. The other perspective focuses on growth of the system, basically implying that economic sustainability can be achieved when there is enough return on invested capital. In this perspective, a distinction is made between weak and strong sustainability, depending on how natural and economic capital are combined in the evaluation $[29,30]$. In weak sustainability the two kinds of capital are combined, while in strong sustainability they are evaluated separately [30].

\subsubsection{Social Sustainability}

The least well-defined sustainability dimension is the social sustainability. This is also the dimension that most often goes unnoticed [31]. Social sustainability can be defined as societal progress of processes and structures to meet the needs of today and, at the same time, create a base for further sustainable development in the future. In this project, the term social sustainability covered social equity, health equity, livelihood, labor rights, community development, and community resilience. Animal health and animal welfare were also included, as these aspects are important for consumer acceptance of beef and lamb meat production.

\subsection{Systematic Mapping Approach}

In this project, a systematic mapping approach was used for the analysis. This is a transparent, robust, and repeatable method which provides an organized compilation of published papers in the topic of interest [32,33], but without further synthesis or processing of the study results [34]. Instead, systematic mapping is used to identify and collect the published papers within a particular research topic and to identify knowledge gaps where future research is needed. A systematic review, on the other hand, aims to answer a specific research question [34] by collecting relevant papers and to synthesize the results using a suitable method, e.g., meta-analysis [33,34]. A full systematic review was not the aim of this study but, in addition to the systematic mapping, data was extracted from the mapped literature to identify which aspects of the three sustainability dimensions that were included in each study. In the analytical process, the extracted keywords were compiled and categorized to get a picture of which aspects that were studied.

\subsection{Literature Search}

To obtain an unbiased selection of published papers dealing with sustainability at farm-level in beef and lamb meat production, a comprehensive search of available literature databases was conducted. The online databases used for this purpose were Web of Science Core Collection, CABI: Cab Abstracts, and Scopus. The searches were restricted to literature published between 1 January 2000 and 27 August 2020.

In order to identify relevant articles in relation to sustainability at farm-level in beef and lamb meat production, the following species-specific search strings were used: '(beef OR steer OR steers OR cattle OR heifer* OR "dairy bull*" OR "dairy breed" OR "suckler $\mathrm{cow}^{*}$ " OR “cattle herd*")' and '(ewe* OR lamb* OR ram OR rams OR sheep OR wether" 
OR "sheep meat")'. The species-specific search strings were then used in combination with search strings for the three dimensions of sustainability (Table 1). The searches for beef and lamb were conducted separately for each species.

Table 1. The search stings used to identify papers studying environmental, economic, and social sustainability at farm-level in beef and lamb meat production.

\begin{tabular}{|c|c|}
\hline $\begin{array}{l}\text { Sustainability } \\
\text { Dimension }\end{array}$ & Search Strings 1 \\
\hline Environmental & 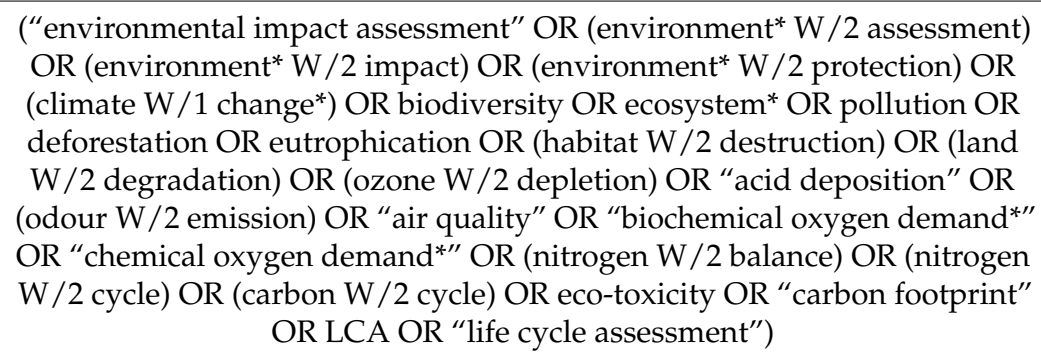 \\
\hline Economic & $\begin{array}{c}\text { ((agricultur* W/2 development) OR (agricultur* W/2 production) OR } \\
\text { (farm* W/2 comparison*) OR (farm W/2 entrant*) OR (farm W/2 result*) } \\
\text { OR (farm W/2 development) OR production OR diversification OR } \\
\text { intensification OR “technical efficiency" OR “economic efficiency" OR } \\
\text { "eco-efficiency" OR profit OR econom* OR return OR "economic viability" } \\
\text { OR "economic performance") }\end{array}$ \\
\hline Social & $\begin{array}{l}\text { ((attitude* W/2 work) OR labour OR labor OR (quality W/2 life) OR } \\
\text { "living condition*" OR "rural welfare" OR (work* W/2 condition*) OR } \\
\text { "rural development" OR "social welfare" OR "social security" OR “social } \\
\text { service*" OR “social equity" OR (health W/2 service*) OR “social status" } \\
\text { OR (women W/2 status) OR "equal right*" OR equality OR (rural W/2 } \\
\text { employment) OR livability OR "health equity" OR "labour rights" OR } \\
\text { "labor rights" OR “social justice" OR “social capital" OR (community W/2 } \\
\text { development) OR (community W/2 resilience)) }\end{array}$ \\
\hline
\end{tabular}

${ }^{1}$ The Boolean operator $\mathrm{W}$ was used for the search in Scopus, while the Boolean operator NEAR was used for the searches in Web of Science Core Collection and CABI: CAB Abstracts.

On completion of the searches, the results from each database were imported into a separate library in EndNote $\mathrm{X}^{\mathrm{TM}}$. For each individual search, the number of hits was recorded. Before the review process, one single library was created for beef and lamb, respectively. The automatic function in EndNote $\mathrm{X} 8^{\mathrm{TM}}$ were then used to remove duplicate papers. Then, the libraries were manually scanned for papers dealing with sustainability at farm-level in beef and lamb meat production.

To be included in the systematic mapping, the papers had to be full-length, trial-based papers written in English. Further, papers had to originate from Europe, Northern America, or Australia-New Zealand.

\section{Results}

In total, 1009 hits related to beef cattle and 346 related to lamb were obtained (Table 2). After duplicates were removed and papers that did not fit the scope of the systematic mapping, i.e., papers dealing with dairy (both cattle and sheep) or wool production, conference abstracts, review papers, book chapters, non-peer-reviewed reports, and articles not written in English, were excluded a total of 22 and 11 papers dealing with beef cattle and lamb, respectively remained (Appendix A). These 33 papers were included in the analysis and categorized based on which aspects of sustainability that were studied. Of the included studies, three quarters were conducted in Europe (Table 3). 
Table 2. Total number of hits in the databases used (duplicates and literature other than peer-reviewed articles included).

\begin{tabular}{ccccc}
\hline & \multicolumn{2}{c}{ Cattle } & \multicolumn{2}{c}{ Sheep } \\
\cline { 2 - 5 } & No. & $\%$ & No. & \% \\
\hline CABI: Cab Abstracts & 522 & 52 & 175 & 51 \\
Scopus & 259 & 26 & 94 & 27 \\
Web of Science Core Collection & 228 & 22 & 77 & 22 \\
Total & 1009 & 100 & 346 & 100 \\
\hline
\end{tabular}

Table 3. Number of papers included in the systematic mapping dealing with one or more of the sustainability dimensions, based on geographical origin.

\begin{tabular}{ccccccc}
\hline & \multicolumn{2}{c}{ Europe } & \multicolumn{2}{c}{ Northern America } & \multicolumn{2}{c}{ Australia \& New Zealand } \\
\cline { 2 - 7 } & Cattle & Sheep & Cattle & Sheep & Cattle & Sheep \\
\hline Total & 14 & 11 & 6 & 0 & 2 & 0 \\
Environmental & 7 & 5 & 4 & 0 & 2 & 0 \\
Economic & 10 & 7 & 6 & 0 & 1 & 0 \\
Social & 9 & 9 & 4 & 0 & 0 & 0 \\
All three & 6 & 3 & 2 & 0 & 0 & 0 \\
dimensions & & & & & & \\
\hline
\end{tabular}

The articles included in the systematic mapping were evaluated based on the three sustainability dimensions and whether all three dimensions, or just one or two, were part of the paper. While reading, we discovered that in some papers aspects of environmental, economic or social sustainability were merely mentioned, e.g., in the abstract or introduction, but were not actually studied. It was also common for one or two dimensions to be discussed only briefly in relation to that/those actually measured and analyzed.

In the final set of papers, $40 \%$ of those dealing with beef cattle and $27 \%$ of those dealing with sheep had actually studied all three sustainability dimensions (Table 3).

In the mapping process, keywords describing aspects of the sustainability dimensions dealt with in each study were identified and categorized (Figure 1).

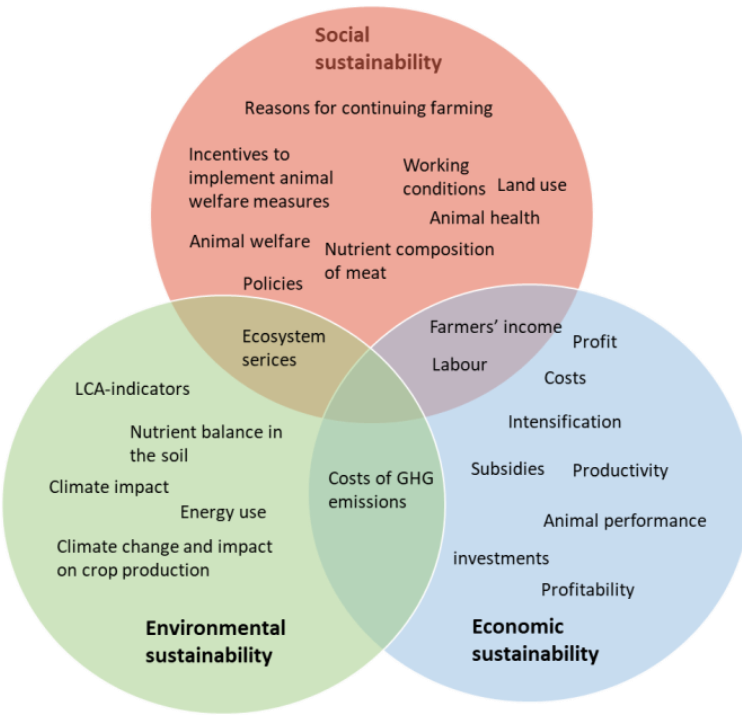

(a)

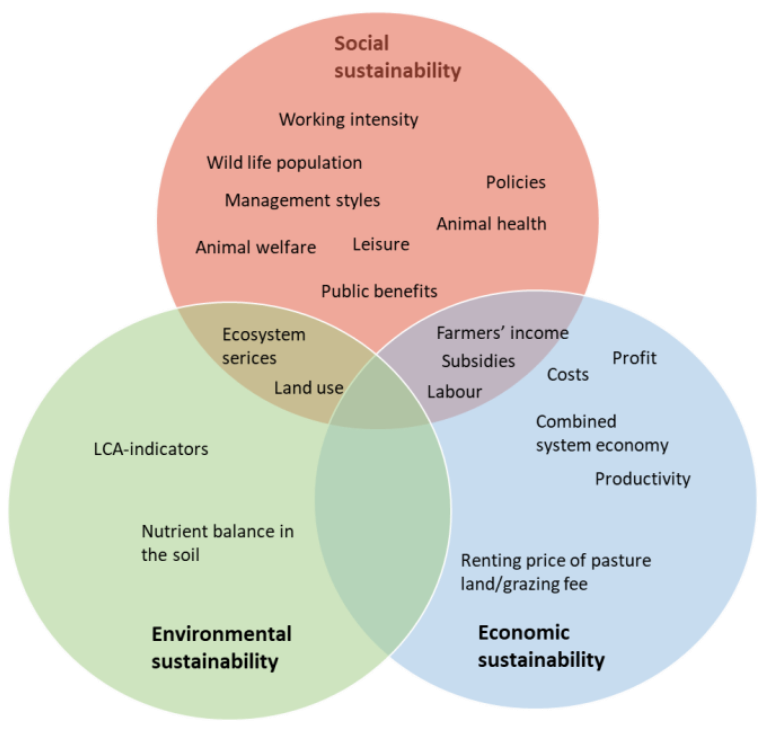

(b)

Figure 1. Categorized keywords identified from articles studying, or mentioning, aspects of environmental, economic and social sustainability in (a) beef cattle and (b) sheep/lamb meat farming. Keywords in the intersections of dimensions refer to sustainability aspects that were related to more than one sustainability dimension. 
When it comes to environmental sustainability in beef cattle production, the main focus was on GHG emissions and nutrient balance in the soil. Variables most often studied in relation to GHG emissions were different rearing systems, e.g., grazing different types of pasture and indoor feeding. Biodiversity was also included in several papers. One paper included renewable energy sources and energy use. In papers dealing with sheep, the main focus was on biodiversity and there was a much smaller focus on GHG emissions than in papers studying beef cattle.

Economic sustainability in relation to beef cattle production was most often measured as farmers' income and farm profitability comparing different production systems, focusing on different feeding strategies and rearing systems. Economic sustainability also included incomes generated by subsidies. Animal performance, such as age at weaning and average daily gain, and production costs for feeds (grass and cereals) were included in economic sustainability. One study focused on the opportunity cost of land if oat for producing oat drink were grown instead of producing beef meat. In the sheep papers, the focus was on farmer income. In addition, the cost of leasing pastureland and grazing fees were studied.

A wide variety of aspects were covered in the papers including social sustainability. Several studies included aspects such as farmers' income, labor costs, and working conditions (workload, working hours). Further, depopulation of rural areas, nutritional composition of the meat, and reasons for continuing farming were studied. In addition, policies and regulations and government budgets for subsidies were studied. One paper dealing with sheep farming concluded that systems for subsidies promoted a divergence between two social groups (in this case cultivators and pastoralists).

Five of the papers dealing with beef cattle included animal welfare in the sustainability measures, while three of the sheep papers did so. Aspects raised in in relation to animal welfare were stocking density, implementations of animal-based policies, animal health and wellbeing, and societal concerns about animal welfare.

Among the papers dealing with beef cattle, 50\% were based on modeling, scenario analyses, and/or analysis of already existing data (Figure 2). Among the papers dealing with sheep the proportion was similar (44\%) (Figure 2). A vast majority of the papers ( $84 \%$ for beef cattle and all but one for sheep) regarded today as the time perspective. The remaining sheep paper and $5 \%$ of the beef cattle papers were looking to the future, $5 \%$ compared the past with the present, and 5\% covered the whole span of past, present, and future.

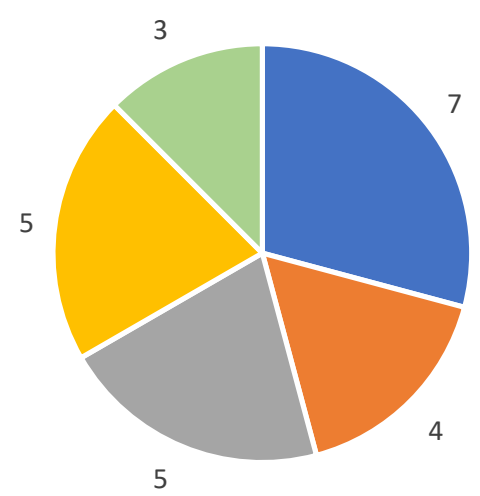

(a)

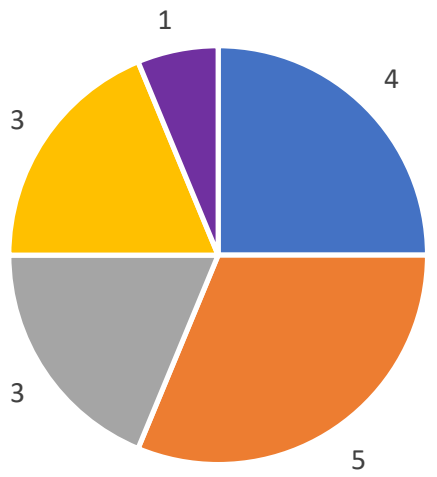

(b)

\footnotetext{
- Modelling, scenario analysis

- On farm studies, incl. Comparison between systems

- LCA
}

Figure 2. Type of methodology used in the studies included in the systematic mapping covering (a) beef cattle and (b) sheep/lamb meat farming. Some studies were based on one or more methodologies and can therefore appear in more than one category. 


\section{Discussion}

The systematic mapping approach used in this study provided a structured overview of the present state of knowledge regarding environmental, economic, and social sustainability on farm-level in beef and lamb production. Based on these results, knowledge gaps can be identified and priority areas for future research can be discussed. During the mapping process, we found that almost $40 \%$ of the beef papers and barely $30 \%$ of the sheep papers included in the analysis covered all three sustainability dimensions simultaneously. This was a surprisingly low number, bearing in mind that sustainability has been on the agenda for over 30 years and that beef and lamb meat farming is an important share of global livestock production. However, in previous systematic mappings we detected a similar trend among papers covering sustainability on farm-level in other species [23-26]. It was more common for papers to cover one or two of the sustainability dimensions. Overall, the economic dimension was covered by around $80 \%$ of both beef cattle and sheep papers, thereby making it the most commonly considered sustainability dimension in beef cattle and sheep farming papers. The currently slim economic margins in beef cattle and sheep farming are a likely reason for the evident interest in farm-level economic sustainability. Furthermore, beef cattle and lamb meat production today poses environmental sustainability challenges, mainly due to emissions of GHG. The importance of this matter could be seen in the beef cattle studies, where nine of the thirteen papers that included environmental sustainability studied GHG emissions. However, only one of the six sheep papers that included environmental sustainability studied GHG emissions, and instead biodiversity and land use were the main aspects of environmental sustainability considered. Social sustainability was studied to a larger extent in the beef cattle and sheep papers than previously observed in systematic mappings of dairy [23], pig [24], finfish [25] and egg and chicken meat [26] production.

Throughout the mapping process, keywords describing sustainability aspects covered in each paper were extracted and categorized. A major challenge during this process was the diversity of aspects used to define and describe sustainability in the different studies. As an example, 'economic sustainability' was used in relation to everything from the farmers' income in a specific rearing system to aspects relating to the common agricultural policy of the European Union. For the term 'social sustainability', the variety of aspects included was even wider, probably due to the fact that there is no common definition of this dimension. This wide variety of aspects, combined with the wide variety of approaches used in the papers included, made it difficult to compare the studies. During the mapping process in the work presented here, and also in our previous mappings of dairy [23], pig [24], and egg and chicken meat [26] production, it became apparent that a prioritized area for the future should be to develop a uniform definition and nomenclature for different aspects of sustainability. Standardized nomenclature would facilitate comparisons of results from different studies and help to draw more general conclusions.

From the start, animal welfare was not included as an aspect of sustainability and, hence, it was not included in our search strings. It was, however, added as a part of sustainability during the analysis of the included papers. As a concept, animal welfare consists of many different aspects and can be considered part of all three dimensions (environmental, economic, and social) of sustainability. For example, Nieto et al. [35] measured performance and GHG emissions of beef production and found lower emissions on farms with higher standards of animal welfare. Improving the welfare of beef cattle and sheep is a way of ensuring high productivity and, at the same time, minimize the GHG emission per $\mathrm{kg}$ of meat produced [36]. Improved animal health and animal productivity can also enhance the economic sustainability of production [37,38]. Animal welfare has in fact been suggested as an dimension of sustainability on its own [39]. However, in this work animal welfare was included in social sustainability. There is a growing awareness of animal wellbeing among the general public [21,22], an issue which is hence closely linked to societal view and acceptance of livestock production. Further, animals are living beings and as such they are part of the social system on the farm, and of society as a whole, so animal 
welfare can be considered to belong to the social dimension of sustainability. With this in mind, it is likely that other aspects of sustainability can be interconnected in a similar way. During the mapping process, it became clear that the existing literature to date does not consider or describe these occurring connections. Moreover, possible positive or negative interrelations between the various aspects of the different dimensions of sustainability are not discussed. This should be highlighted and prioritized in the coming future.

In addition to the sustainability dimensions so far covered in this paper, governance, or institutional, sustainability has been identified as a part of the sustainability concept $[40,41]$. Governance sustainability has been defined the rules that govern human interrelations in a society [41]. Without supervision, there is a risk that the other dimensions of sustainability will not always be maintained [18]. Beef cattle and sheep farming, which includes animal husbandry, grazing and crop production, is regulated both nationally and internationally. Therefore, it would be of value to also include governance sustainability when assessing farm-level sustainability in beef and lamb meat production. Apart from a study by Paraskevopoulou et al. [18], this dimension was not mentioned in any of the papers included in the mapping. However, in some of the papers aspects such as policies was included in the within the social dimension and subsidies within the framework of economic sustainability, although both policies and subsidies clearly should be included in the governance dimension.

Nearly half of the articles included in the mapping were based on analysis of existing data, scenario analysis, or modelling. The same trend was seen among papers studying sustainability at farm-level in relation to dairy production [23]. These are efficient approaches to study the effects of different management strategies, including e.g., animal rearing, grazing management and cropping systems, on environmental impact or economic outcomes. However, when using these methods, it is crucial that the calculations are based on data that is valid and up-to-date in order to obtain representative estimates. Further, conditions for agricultural systems and practices differ in e.g., precipitation, temperature and soil types, both between countries and between regions within countries. In addition, laws and regulations differ between countries, which affects beef and lamb meat production in general and perhaps the economics of beef and lamb farming in particular. With this in mind is it even more important to make sure that the calculations are based on data which is valid for the conditions and production systems where the outcomes are to be applied. Otherwise, there is a risk that the measures, based on the results, implemented on the farms will not have the desired effect and hence not contribute to a sustainable development of beef and lamb production.

\section{Study Limitations and Future Research Prospectives}

In order to get as comprehensive search results as possible in systematic mapping, the design of the search strings is crucial. In the present study, we included search terms for environmental, economic, and social sustainability in the searches, but found that just a small share of the papers identified covered the three dimensions of sustainability simultaneously. However, no library search is comprehensive enough to cover all conceivable terms for the topic of interest. Hence, there might be more published papers covering these issues that did not appear in our searches, since they might not have included the exact terms and indicators present in our search stings. It is a challenge to create a search string that is inclusive and at the same time specific enough to find papers relevant for the area of interest. Another obstacle might be the format in which we normally publish research results today. Sustainability is a very complex concept and studies including several aspects may not fit into the common format. Large, complex studies tend instead to be published in several, separate papers with each paper dealing with one of the different sustainability dimensions. Consequently, there might be relevant articles that we missed in the searches. However, since the search strings developed and used in this study can be considered extensive, we believe that they identified most of the published scientific literature covering sustainability at farm-level in beef and lamb meat production. 
As a result of this study, we were able to identify a number of knowledge gaps that may form the basis for further discussions about future research needs and measures that needs to be taken and there are a few points we would like to raise.

Firstly, it emerged that there are just a small number of published papers that actively include all three dimensions of sustainability simultaneously in relation to beef and lamb production. In the present study, just under half of the papers identified included both environmental, economic and social sustainability. In a number of papers, one or two of the dimensions were not actually studied but just set in relation to the one/ones measured, thus limiting the extent to which associations between different sustainability dimensions can actually be studied. Further, 19 of the total 33 included papers were based on analysis of existing data, modelling, or scenario analysis. This indicates a need for a more comprehensive approach when studying farm-level sustainability in beef and lamb meat production.

Secondly, we found that, in the set of papers mapped, there was a large diversity of aspects used to define and describe farm-level sustainability in beef and lamb meat production. In addition, just one paper included aspects of governance sustainability. However, in several papers aspects related to this dimension were included in the framework of social and/or economic sustainability instead. Due to the large diversity of aspects included in different studies, it is hard, or even impossible, to make useful comparisons of studies and to draw further conclusions. Once again, future research would benefit from a more holistic approach and include all dimensions of sustainability, including the governance dimension, and analyze them simultaneously and on the same level within a particular study. Further, focus should also be on how to measure and assess sustainability dimensions, and individual aspects within them, in a standardized way.

Thirdly, none of the identified papers showed or explained any possible interrelations between different aspects of sustainability. Hence, potential synergies or negative effects between aspects, both between dimensions but also within dimensions, still needs to be investigated. A better understanding of these interrelations and interactions would be an important piece of the puzzle in the work on determining how to improve individual aspects of sustainability but also how the entire farm-level sustainability can develop in a positive way.

Author Contributions: For research articles with several authors, a short paragraph specifying their individual conceptualization, S.G., H.H., U.S., K.A.S. and investigation, K.A.S.; data curation, K.A.S.; formal analysis, K.A.S.; writing — original draft preparation, K.A.S.; review and editing, H.H., U.S., and S.G.; funding acquisition, S.G. All authors have read and agreed to the published version of the manuscript.

Funding: This research was funded by The Swedish Research Council Formas, grant number 2017-02017.

Institutional Review Board Statement: Not applicable.

Informed Consent Statement: Not applicable.

Data Availability Statement: No new data were created or analyzed in this study. Data sharing is not applicable to this article.

Acknowledgments: We thank Mattias Lennartsson, librarian at the Swedish University of Agricultural Sciences, for valuable help during the process of developing the search strings.

Conflicts of Interest: The authors declare no conflict of interest. The funders had no role in the design of the study; in the collection, analyses, or interpretation of data; in the writing of the manuscript, or in the decision to publish the results. 


\section{Appendix A}

Papers included in the systematic mapping:

Beef cattle

1. Alary, V.; Moulin, C.-H.; Lasseur, J.; Aboul-Naga, A.; Sraïri, M.T. The dynamic of crop-livestock systems in the Mediterranean and future prospective at local level: A comparative analysis for South and North Mediterranean systems. Livest. Sci. 2019, 224, 40-49, doi:10.1016/j.livsci.2019.03.017.

2. Blanco-Fontao, B.; Quevedo, M.; Obeso, J.R. Abandonment of traditional uses in mountain areas: typological thinking versus hard data in the Cantabrian Mountains (NW Spain). Biodivers. Conserv. 2011, 20, 1133-1140, doi:10.1007/s10531-011-0016-1.

3. Burggraaf, V.T.; Craigie, C.R.; Muir, P.D.; Khan, M.A.; Thomson, B.C.; Knol, F.W.; Lowe, K.A.; Taukiri, K.R.; Staincliffe, M.; McDermott, A.; et al. Effect of rearing diet and early post-weaning pasture quality on the life-time growth, meat quality, carcass traits and environmental impact of dairy-beef cattle. Livest. Sci. 2020, 239, 104031, doi:10.1016/j.livsci.2020.104031.

4. Dunn, B.H.; Smart, A.J.; Gates, R.N.; Johnson, P.S.; Beutler, M.K.; Diersen, M.A.; Janssen, L.L. Long-Term Production and Profitability From Grazing Cattle in the Northern Mixed Grass Prairie. Rangel. Ecol. Manag. 2010, 63, 233-242, doi:10.2111/REMD-09-00042.1.

5. Escribano, A.J.; Gaspar, P.; Mesías, F.J.; Escribano, M. The role of the level of intensification, productive orientation and self-reliance in extensive beef cattle farms. Livest. Sci. 2016, 193, 8-19, doi:10.1016/j.livsci.2016.09.006.

6. González Díaz, J.A.; Celaya, R.; Fernández García, F.; Osoro, K.; Rosa García, R. Dynamics of rural landscapes in marginal areas of northern Spain: Past, present, and future. Land Degrad. Dev. 2019, 30, 141-150, doi:10.1002/ldr.3201.

7. Hussain, A.M.T.; Tschirhart, J. Economic/ecological tradeoffs among ecosystem services and biodiversity conservation. Ecol. Econ. 2013, 93, 116-127, doi:10.1016/ j.ecolecon.2013.04.013.

8. Lehtonen, H.S. Evaluating adaptation and the production development of Finnish agriculture in climate and global change. Agric. Food Sci. 2015, 24, 219-234, doi:10.23986/ afsci.51080.

9. López-i-Gelats, F.; Bartolomé Filella, J. Examining the role of organic production schemes in Mediterranean pastoralism. Environ. Dev. Sustain. 2020, 22, 5771-5792, doi:10.1007/s10668-019-00450-0.

10. Morgan-Davies, C.; Wilson, R.; Waterhouse, T. Impacts of farmers' management styles on income and labour under alternative extensive land use scenarios. Agric. Syst. 2017, 155, 168-178, doi:10.1016/j.agsy.2017.04.011.

11. Mosnier, C.; Duclos, A.; Agabriel, J.; Gac, A. Orfee: A bio-economic model to simulate integrated and intensive management of mixed crop-livestock farms and their greenhouse gas emissions. Agric. Syst. 2017, 157, 202-215, doi:10.1016/j.agsy.2017.07.005.

12. Pietzsch, D.; Ochsner, S.; Mantilla-Contreras, J.; Hampicke, U. Low-intensity Husbandry as a Cost-efficient Way to Preserve Dry Grasslands. Landsc. Res. 2013, 38, 523-539, doi:10.1080/01426397.2012.741223.

13. Rebhann, M.; Karatay, Y.N.; Filler, G.; Prochnow, A. Profitability of Management Systems on German Fenlands. Sustainability 2016, 8, 1103, doi:doi.org/10.3390/su8111103.

14. Röös, E.; Patel, M.; Spångberg, J. Producing oat drink or cow's milk on a Swedish farm - Environmental impacts considering the service of grazing, the opportunity cost of land and the demand for beef and protein. Agric. Syst. 2016, 142, 23-32, doi:10.1016/j.agsy.2015.11.002.

15. Röös, E.; Patel, M.; Spångberg, J.; Carlsson, G.; Rydhmer, L. Limiting livestock production to pasture and by-products in a search for sustainable diets. Food Policy 2016, 58, 1-13, doi:10.1016/j.foodpol.2015.10.008. 
16. Santeramo, F.G.; Lamonaca, E.; Tappi, M.; Di Gioia, L. Considerations on the Environmental and Social Sustainability of Animal-Based Policies. Sustainability 2019, 11, 2316, doi:10.3390/su11082316.

17. Schroeder, L.A.; Gocht, A.; Britz, W. The Impact of Pillar II Funding: Validation from a Modelling and Evaluation Perspective. J. Agric. Econ. 2015, 66, 415-441, doi:10.1111/1477-9552.12091.

18. Wang, T.; Jin, H.; Kreuter, U.; Feng, H.; Hennessy, D.A.; Teague, R.; Che, Y. Challenges for rotational grazing practice: Views from non-adopters across the Great Plains, USA. J. Environ. Manag. 2020, 256, 109941, doi:10.1016/j.jenvman.2019.109941.

19. Wang, T.; Park, S.C.; Bevers, S.; Teague, R.; Cho, J. Factors Affecting Cow-Calf Herd Performance and Greenhouse Gas Emissions. J. Agric. Resour. Econ. 2013, 38, 435-456.

20. White, T.A.; Snow, V.O.; King, W.M. Intensification of New Zealand beef farming systems. Agric. Syst. 2010, 103, 21-35, doi:10.1016/j.agsy.2009.08.003.

21. Wiltshire, K.; Delate, K.; Flora, J.; Wiedenhoeft, M. Socio-cultural aspects of cow-calf operation persistence in a peri-urban county in Iowa. Renew. Agric. Food Syst. 2011, $26,60-71$.

22. Zilverberg, C.J.; Johnson, P.; Weinheimer, J.; Allen, V.G. Energy and Carbon Costs of Selected Cow-Calf Systems. Rangel. Ecol. Manag. 2011, 64, 573-584, doi:10.2111/REMD-10-00190.1.

Sheep/lamb

1. Caballero, R.; Riseth, J.Å.; Labba, N.; Tyran, E.; Musial, W.; Molik, E.; Boltshauser, A.; Hofstetter, P.; Gueydon, A.; Roeder, N.; et al. Comparative Typology in Six European Low-Intensity Systems of Grassland Management. In Advances in Agronomy; Academic Press: Cambridge, MA, USA, 2007; Volume 96, pp. 351-420.

2. Cammerino, A.R.B.; Biscotti, S.; De Iulio, R.; Monteleone, M. The sheep tracks of transhumance in the Apulia region (south Italy): Steps to a strategy of agricultural landscape conservation. Appl. Ecol. Environ. Res. 2018, 16, 6977-7000, doi:10.15666/aeer/1605_69777000.

3. Mansard, L.; Vigan, A.; Meuret, M.; Lasseur, J.; Benoit, M.; Lecomte, P.; Eugène, M. An enteric methane emission calculator (DREEM) built to consider feed diversity: Case study of pastoral and sedentary farming systems. Small Rumin. Res. 2018, 167, 6-15, doi:10.1016/j.smallrumres.2018.07.024.

4. Morgan-Davies, C.; Wilson, R.; Waterhouse, T. Impacts of farmers' management styles on income and labour under alternative extensive land use scenarios. Agric. Syst. 2017, 155, 168-178, doi:10.1016/j.agsy.2017.04.011.

5. Morgan-Davies, C.; Lambe, N.; Wishart, H.; Waterhouse, T.; Kenyon, F.; McBean, D.; McCracken, D. Impacts of using a precision livestock system targeted approach in mountain sheep flocks. Livest. Sci. 2018, 208, 67-76, doi:10.1016/j.livsci.2017.12.002.

6. Pantera, A.; Burgess, P.J.; Mosquera Losada, R.; Moreno, G.; López-Díaz, M.L.; Corroyer, N.; McAdam, J.; Rosati, A.; Papadopoulos, A.M.; Graves, A.; et al. Agroforestry for high value tree systems in Europe. Agrofor. Syst. 2018, 92, 945-959, doi:10.1007/s10457-017-0181-7.

7. Paraskevopoulou, C.; Theodoridis, A.; Johnson, M.; Ragkos, A.; Arguile, L.; Smith, L.; Vlachos, D.; Arsenos, G. Sustainability Assessment of Goat and Sheep Farms: A Comparison between European Countries. Sustainability 2020, 12, 3099, doi:10.3390/su12083099.

8. Petursdottir, T.; Aradottir, A.L.; Baker, S.; Halldorsson, G.; Sonneveld, B. Successes and Failures in Rangeland Restoration: An Icelandic Case Study. Land Degrad. Dev. 2017, 28, 34-45, doi:10.1002/ldr.2579.

9. Riedel, J.L.; Casasús, I.; Bernués, A. Sheep farming intensification and utilization of natural resources in a Mediterranean pastoral agro-ecosystem. Livest. Sci. 2007, 111, 153-163, doi:10.1016/j.livsci.2006.12.013.

10. Tzouramani, I.; Mantziaris, S.; Karanikolas, P. Assessing Sustainability Performance at the Farm Level: Examples from Greek Agricultural Systems. Sustainability 2020, 12, 2929, doi:10.3390/su12072929. 
11. Wainwright, W.; Glenk, K.; Akaichi, F.; Moran, D. Conservation contracts for supplying Farm Animal Genetic Resources (FAnGR) conservation services in Romania. Livest. Sci. 2019, 224, 1-9, doi:10.1016/j.livsci.2019.03.016

\section{References}

1. UN. Sustainable Development Goals. Available online: https://www.un.org/development/desa/en/news/sustainable/ sustainable-development-goals.html (accessed on 22 February 2019).

2. UN. Global Sustainable Development Report. 2015. Available online: https://sustainabledevelopment.un.org/content/ documents /1758GSDR\%202015\%20Advance\%20Unedited\%20Version.pdf (accessed on 28 August 2020).

3. FAO. FAOSTAT Database. Available online: http://www.fao.org/faostat/en/\#home (accessed on 17 September 2020).

4. Bennett, R.M.; Anderson, J.; Blaney, R.J.P. Moral Intensity and Willingness to Pay Concerning Farm Animal Welfare Issues and the Implications for Agricultural Policy. J. Agric. Environ. Ethics 2002, 15, 187-202. [CrossRef]

5. van Calker, K.J.; Berentsen, P.B.M.; Giesen, G.W.J.; Huirne, R.B.M. Identifying and ranking attributes that determine sustainability in Dutch dairy farming. Agric. Hum. Values 2005, 22, 53-63. [CrossRef]

6. Brundtland, G.H. Our Common Future-Call for Action. Environ. Conserv. 1987, 14, 291-294. [CrossRef]

7. Torp-Donner, H.; Juga, J. Sustainability-A challenge to animal production and breeding. Agric. Food Sci. 1997, 6. [CrossRef]

8. Tilman, D.; Cassman, K.G.; Matson, P.A.; Naylor, R.; Polasky, S. Agricultural sustainability and intensive production practices. Nature 2002, 418, 671-677. [CrossRef] [PubMed]

9. FAO. The State of Food and Agriculture. In Livestock in the Balance; Food and Agricultural Organization of the United Nations: Rome, Italy, 2009; Available online: http: / / www.fao.org/3/i0680e/i0680e.pdf (accessed on 14 April 2020).

10. Broom, D.M. Land and Water Usage in Beef Production Systems. Animals 2019, 9, 286. [CrossRef] [PubMed]

11. Gerber, P.J.; Steinfeld, H.; Henderson, B.; Mottet, A.; Opio, C.; Dijkman, J.; Falcucci, A.; Tempio, G. Tackling Climate Change through Livestock: A Global Assessment of Emissions and Mitigation Opportunities; FAO: Rome, Italy, 2013.

12. Crosson, P.; Shalloo, L.; O’Brien, D.; Lanigan, G.J.; Foley, P.A.; Boland, T.M.; Kenny, D.A. A review of whole farm systems models of greenhouse gas emissions from beef and dairy cattle production systems. Anim. Feed Sci. Technol. 2011, 166-167, 29-45. [CrossRef]

13. Wilkinson, J.M. Reducing greenhouse gas emissions from livestock. UK Vet Livest. 2012, 17, 25-27. [CrossRef]

14. Burggraaf, V.T.; Craigie, C.R.; Muir, P.D.; Khan, M.A.; Thomson, B.C.; Knol, F.W.; Lowe, K.A.; Taukiri, K.R.; Staincliffe, M.; McDermott, A.; et al. Effect of rearing diet and early post-weaning pasture quality on the life-time growth, meat quality, carcass traits and environmental impact of dairy-beef cattle. Livest. Sci. 2020, 239, 104031. [CrossRef]

15. FAO. Livestock's Long Shadow-Environmental Issues and Options; Food and Agricultural Organization of the United Nations: Rome, Italy, 2006; Available online: http:/ / www.fao.org/3/a0701e/a0701e.pdf (accessed on 1 September 2020).

16. Broom, D.M.; Galindo, F.A.; Murgueitio, E. Sustainable, efficient livestock production with high biodiversity and good welfare for animals. Proc. R. Soc. B 2013, 280, 20132025. [CrossRef] [PubMed]

17. Ridoutt, B.G.; Page, G.; Opie, K.; Huang, J.; Bellotti, W. Carbon, water and land use footprints of beef cattle production systems in southern Australia. J. Clean. Prod. 2014, 73, 24-30. [CrossRef]

18. Paraskevopoulou, C.; Theodoridis, A.; Johnson, M.; Ragkos, A.; Arguile, L.; Smith, L.; Vlachos, D.; Arsenos, G. Sustainability Assessment of Goat and Sheep Farms: A Comparison between European Countries. Sustainability 2020, 12, 3099. [CrossRef]

19. Filson, G.C.; Pfeiffer, W.C.; Paine, C.; Taylor, J.R. The Relationship Between Grand River Dairy Farmers' Quality of Life and Economic, Social and Environmental Aspects of Their Farming Systems. J. Sustain. Agric. 2003, 22, 61-77. [CrossRef]

20. Filson, G.C.; McCoy, M. Farmers' Quality of Life: Sorting Out the Differences by Class. Rural Sociol. 1993, 13, 15-37.

21. Ingenbleek, P.T.M.; Immink, V.M. Consumer decision-making for animal-friendly products: Synthesis and implications. Anim. Welf. 2011, 20, 11-19.

22. European Commission. Attitudes of Europeans towards Animal Welfare; Directorate-General for Communication: Brussels, Belgium, 2015; Available online: https:/ / data.europa.eu/euodp/data/dataset/S2096_84_4_442_ENG (accessed on 14 September 2020).

23. Arvidsson Segerkvist, K.; Hansson, H.; Sonesson, U.; Gunnarsson, S. Research on Environmental, Economic, and Social Sustainability in Dairy Farming: A Systematic Mapping of Current Literature. Sustainability 2020, 12, 5502. [CrossRef]

24. Gunnarsson, S.; Arvidsson Segerkvist, K.; Wallgren, T.; Hansson, H.; Sonesson, U. A Systematic Mapping of Research on Sustainability Dimensions at Farm-level in Pig Production. Sustainability 2020, 12, 4352. [CrossRef]

25. Gunnarsson, S.; Arvidsson Segerkvist, K.; Wallgren, T.; Hjelmstedt, P.; Sonesson, U.; Hansson, H. Systematic Mapping of Research on Farm-Level Sustainability in Finfish Aquaculture. Sustainability 2020, 12, 9985. [CrossRef]

26. Gunnarsson, S.; Arvidsson Segerkvist, K.; Göransson, L.; Hansson, H.; Sonesson, U. Systematic Mapping of Research on Farm-Level Sustainability in Egg and Chicken Meat Production. Sustainability 2020, 12, 3033. [CrossRef]

27. Montiel, I.; Delgado-Ceballos, J. Defining and Measuring Corporate Sustainability:Are We There Yet? Organ. Environ. 2014, 27, 113-139. [CrossRef]

28. Alliances, G.S. Global Reporting Initiative. Available online: https://www.globalreporting.org/standards/ (accessed on 5 April 2020).

29. Ayres, R.U.; van den Bergh, J.C.J.M.; Gowdy, J.M. Strong versus weak sustainability: Economics, natural sciences and 'consilience'. Environ. Ethics 2001, 23, 155-168. [CrossRef] 
30. van den Bergh, J.C.J.M. Externality or sustainability economics? Ecol. Econ. 2010, 69, 2047-2052. [CrossRef]

31. Vallance, S.; Perkins, H.C.; Dixon, J.E. What is social sustainability? A clarification of concepts. Geoforum 2011, 42, 342-348. [CrossRef]

32. Snilstveit, B.; Vojtkova, M.; Bhavsar, A.; Stevenson, J.; Gaarder, M. Evidence \& Gap Maps: A tool for promoting evidence informed policy and strategic research agendas. J. Clin. Epidemiol. 2016, 79, 120-129. [CrossRef] [PubMed]

33. Petersen, K.; Vakkalanka, S.; Kuzniarz, L. Guidelines for conducting systematic mapping studies in software engineering: An update. Inf. Softw. Technol. 2015, 64, 1-18. [CrossRef]

34. James, K.L.; Randall, N.P.; Haddaway, N.R. A methodology for systematic mapping in environmental sciences. Environ. Evid. 2016, 5, 7. [CrossRef]

35. Nieto, M.; Barrantes, O.; Privitello, L.; Reiné, R. Greenhouse Gas Emissions from Beef Grazing Systems in Semi-Arid Rangelands of Central Argentina. Sustainability 2018, 10, 4228. [CrossRef]

36. Santeramo, F.G.; Lamonaca, E.; Tappi, M.; Di Gioia, L. Considerations on the Environmental and Social Sustainability of Animal-Based Policies. Sustainability 2019, 11, 2316. [CrossRef]

37. Mie, A.; Andersen, H.R.; Gunnarsson, S.; Kahl, J.; Kesse-Guyot, E.; Rembialkowska, E.; Quaglio, G.; Grandjean, P. Human health implications of organic food and organic agriculture: A comprehensive review. Environ. Health 2017, 16, 22. [CrossRef]

38. Amador, P.; Duarte, I.M.; da Costa, R.P.R.; Fernandes, R.; Prudencio, C. Characterization of Antibiotic Resistance in Enterobacteriaceae From Agricultural Manure and Soil in Portugal. Soil Sci. 2017, 182, 292-301. [CrossRef]

39. Stern, S.; Sonesson, U.; Gunnarsson, S.; Öborn, I.; Kumm, K.-I.; Nybrant, T. Sustainable Development of Food Production: A Case Study on Scenarios for Pig Production. AMBIO J. Hum. Environ. 2005, 34, 402-407. [CrossRef]

40. FAO. SAFA Sustainability Assessment Of Food and Agriculture Systems Guidelines; FAO: Rome, Italy, 2014.

41. Valentin, A.; Spangenberg, J.H. A guide to community sustainability indicators. Environ. Impact Assess. Rev. 2000, 20, 381-392. [CrossRef] 